\title{
A formação do capital social no YouTube: estudo com base em um canal de divulgação científica de questões abordadas pela psicologia
}

\author{
The social capital formation on YouTube: study based on a health \\ psychology video found in one of its Science Channels
}

\section{La formación del capital social en YouTube: estudio fundamentado en un canal de divulgación científica referente a cuestiones abordadas por la psicología}

Maurício de Vargas Corrêa ${ }^{1, a}$

mauricio.correa@ufrgs.br | https://orcid.org/0000-0002-8377-0937

Samile Andréa de Souza Vanz ${ }^{1, b}$

samilevanz@terra.com.br | https://orcid.org/0000-0003-0549-4567

${ }^{1}$ Universidade Federal do Rio Grande do Sul, Faculdade de Biblioteconomia e Comunicação. Porto Alegre, RS, Brasil.

a Mestrado em Comunicação e Informação pela Universidade Federal do Rio Grande do Sul.

${ }^{b}$ Doutorado em Comunicação e Informação pela Universidade Federal do Rio Grande do Sul.

\section{Resumo}

Este artigo discute a influência que o conteúdo publicado no YouTube exerce na formação do capital social, a partir da análise do vídeo mais popular de um canal de divulgação científica de questões abordadas pela psicologia e dos comentários a ele associados. Na análise dos comentários, foram utilizados os procedimentos metodológicos da teoria fundamentada. No final da pesquisa, foram identificadas três práticas discursivas que, no contexto de estudo, contribuem para a formação do capital social e de valores a ele relacionados. As formas de capital social encontradas com mais frequência foram a do capital relacional, do capital cognitivo e a da confiança no ambiente social. Entre os valores construídos pelos usuários em suas práticas discursivas estão a visibilidade, a legitimação e o suporte social. Esse último merece destaque por perpassar todas as categorias principais. Concluímos que o conteúdo do vídeo funciona como catalisador para diferentes práticas sociais que culminam na formação do capital social.

Palavras-chave: Capital social; Mídias sociais; Conteúdo gerado pelo usuário; YouTube; Teoria fundamentada. 


\begin{abstract}
This article discusses the influence of YouTube content on the formation of social capital from the analysis of the most popular psychology video on Brazilian Science YouTube Channel and also of the comments made by its users. In the analysis of the comments, the methodological procedures of the grounded theory were used. At the end of the research, three discursive practices were identified and in the study context they aid in the formation of social capital and of related values. The most frequent forms of social capital that we found were those of the relational capital, of the cognitive capital and of the trustworthiness in the interaction with other people in that social environment. Among the values constructed by users in their discursive practices are visibility, legitimation and social support. The latter deserves special mention because it intersects all the main categories. We have come to the conclusion that the content of the video serves as catalyst for different social practices that culminate in the formation of social capital.
\end{abstract}

Keywords: Social capital; Social media; User-generated content; YouTube; Grounded theory.

\title{
Resumen
}

Este artículo discute la influencia del contenido publicado en YouTube sobre la formación del capital social, fundamentada en el análisis del vídeo más popular de un canal de divulgación científica de cuestiones abordadas por la psicología y en los comentarios a él asociados. En el análisis de los comentarios, se utilizaron los procedimientos metodológicos de la teoría fundamentada. En el final de la investigación, se identificaron tres prácticas discursivas que, en el contexto del estudio, contribuyen a la formación del capital social y de valores relacionados a él. Las formas de capital social encontradas con más frecuencia fueron la del capital relacional, del capital cognitivo y de la confianza en el ambiente social. Entre los valores construidos por los usuarios en sus prácticas discursivas están la visibilidad, la legitimación y el apoyo social. Este último merece destacarse por atravesar todas las categorías principales. Concluimos que el contenido del vídeo funciona como catalizador para diferentes prácticas sociales que culminan en la formación del capital social.

Palabras clave: Capital social; Medios sociales; Contenido generado por el usuário; YouTube; Teoría Fundamentada.

\author{
Contribuição dos autores: \\ Concepção e desenho do estudo: Maurício de Vargas Corrêa \\ Aquisição, análise ou interpretação dos dados: Maurício de Vargas Corrêa \\ Redação do manuscrito: Maurício de Vargas Corrêa \\ Revisão crítica do conteúdo intelectual: Samile Andréa de Souza Vanz \\ Declaração de conflito de interesses: não há. \\ Fontes de financiamento: Coordenação de Aperfeiçoamento de Pessoal de Nível Superior (Capes). \\ Considerações éticas: não há.
}

Agradecimentos/Contribuições adicionais: Os autores agradecem à Coordenação de Aperfeiçoamento de Pessoal de Nível Superior (Capes) pelo apoio financeiro à pesquisa.

Histórico do artigo: submetido: 16 fev. 2019 | aceito: 04 fev. 2020 | publicado: 31 mar. 2020.

Apresentação anterior: não houve.

Licença CC BY-NC atribuição não comercial. Com essa licença é permitido acessar, baixar (download), copiar, imprimir, compartilhar, reutilizar e distribuir os artigos, desde que para uso não comercial e com a citação da fonte, conferindo os devidos créditos de autoria e menção à Reciis. Nesses casos, nenhuma permissão é necessária por parte dos autores ou dos editores. 


\section{Introdução}

O YouTube está em segundo lugar entre os sites mais populares no Brasil ${ }^{1}$. Além de oferecer diversas opções de conteúdo audiovisual, um dos recursos disponíveis aos usuários é o campo para comentários sobre os vídeos publicados. As interações estabelecidas nesse espaço permitem a emergência de determinadas práticas sociais que são muito características do contexto atual e demandam uma atenção maior dos pesquisadores pelo seu impacto na sociabilidade contemporânea, tais como o intercâmbio de informações, a construção de redes sociais e a formação do capital social.

O capital social é um conceito sociológico usado para representar uma série de recursos ou valores construídos, obtidos e compartilhados a partir da participação dos indivíduos em um determinado grupo. As interações sociais são consideradas a base para a construção e o acesso a esses recursos que se manifestam de diferentes formas. Com o passar do tempo, pesquisadores perceberam que o conceito de capital social poderia ser aplicado no estudo de fenômenos e comportamentos sociais emergentes a partir do uso das tecnologias da informação e da comunicação e que a apropriação da internet e das mídias sociais têm gerado novas formas de capital social² .

Um dos aspectos que parece mobilizar o comportamento dos indivíduos e, consequentemente, contribuir para a formação do capital social é a publicação de conteúdos no ambiente digital. As informações de caráter científico são um bom exemplo de conteúdo que tende a causar impacto na opinião pública e no cotidiano das pessoas por conta de sua presumida credibilidade e relevância social.

Tendo em vista a carência de estudos relacionando a publicação de conteúdos científicos e a formação do capital social na internet, verificada por meio de buscas bibliográficas, o presente estudo teve por objetivo compreender qual a influência do conteúdo do vídeo mais popular de um canal de divulgação científica do YouTube sobre a formação do capital social naquele contexto particular.

Na próxima seção, são apresentadas as concepções do capital social na visão de teóricos pioneiros na abordagem do tema, bem como as categorias identificadas na literatura recente sobre o conceito que foram usadas na análise e interpretação dos dados da pesquisa.

\section{Formas e expressões do capital social}

Surgido no campo da sociologia, o conceito de capital social tem sido utilizado por pesquisadores de diversas áreas para explicar determinados fenômenos e processos sociais que, mesmo sendo compreendidos por agentes singulares (indivíduos), não poderiam ser reduzidos às propriedades possuídas por um agente determinado ${ }^{3}$. O termo foi empregado pela primeira vez, em 1916, por Lyda J. Hanifan para definir um conjunto de relações caracterizadas pela boa vontade, camaradagem e simpatia. Mais tarde, em 1961, a expressão aparece novamente na obra Morte e vida de grandes cidades, de Jane Jacobs. No entanto, foi o sociólogo Pierre Bourdieu que realizou a primeira análise sistemática do conceito no artigo Le capital social: notes provisoires, publicado em $1980^{4}$.

Bourdieu ${ }^{3}$ define o capital social como "[...] o conjunto de recursos atuais ou potenciais que estão ligados à posse de uma 'rede durável de relações' mais ou menos institucionalizadas de interconhecimento e de inter-reconhecimento [...]" (grifo do autor). As redes de relações que tornam possível o acesso ao capital social são resultado de um trabalho de instauração e manutenção, essencial para produzir e reproduzir relações duráveis e úteis, capazes de proporcionar 'lucros materiais e simbólicos' aos envolvidos³ (grifo nosso).

James S. Coleman 5 foi o primeiro autor a explorar o potencial heurístico do conceito de capital social ${ }^{4}$. Para o autor, “o capital social é definido por sua função. Não é uma entidade única, mas uma variedade de entidades diferentes, com dois elementos em comum: todas elas consistem em algum aspecto das estruturas sociais e facilitam certas ações dos atores - sejam atores pessoais ou corporativos - dentro das estruturas. Como outras formas de capital, 
o capital social é produtivo, possibilitando a realização de determinados objetivos que, na sua ausência, não seria possível" (tradução nossa) $)^{5}$

Um autor amplamente citado em estudos que abordam o conceito de capital social é Robert Putnam. Em sua obra Making democracy work, o conceito de capital social é compreendido como "[...] características da organização social, como confiança, normas e redes, que podem melhorar a eficiência da sociedade facilitando ações coordenadas [...]”. De certo modo, as três definições apresentadas acima destacam o papel das redes sociais na constituição do capital social.

Outras definições podem ser encontradas na literatura. Contudo, optamos por abordar esses três conceitos principais, pois são amplamente utilizados em trabalhos que abordam as redes sociais7. Para os propósitos deste estudo, o capital social será definido aqui como um termo guarda-chuva usado para representar uma série de recursos e valores que são criados, obtidos e compartilhados a partir de interações sociais estabelecidas em contextos online e offline.

Embora Pierre Bourdieu não tenha abordado esse aspecto em sua obra ${ }^{3}$ aqui mencionada, alguns autores se dedicaram à tarefa de identificar as formas que o capital social pode assumir. Bertolini e Bravo ${ }^{8}$ identificaram cinco categorias, passíveis de observação empírica, que representam os diferentes aspectos do capital social, quais sejam:

a) capital social relacional: a soma das relações e das trocas que conectam os indivíduos em um determinado contexto;

b) capital social normativo: diz respeito às regras, normas de comportamento e valores internalizados pelos indivíduos;

c) capital social cognitivo: corresponde ao conhecimento compartilhado e às informações relativas aos problemas enfrentados por um determinado indivíduo ou grupo;

d) confiança no ambiente social: se refere à confiança no comportamento dos indivíduos que fazem parte de um mesmo contexto;

e) capital social institucional: representado pelas instituições de caráter formal e informal, que contribuem para reduzir a incerteza em relação ao comportamento dos indivíduos e elevar os níveis de coordenação e de cooperação.

O capital social gerado a partir da apropriação das ferramentas de comunicação mediada pelo computador contribui para a emergência de determinados valores que, por sua vez, podem influenciar o comportamento dos indivíduos que usam essas plataformas. Em seus estudos sobre redes sociais na internet, Recuero ${ }^{2,7}$ identificou alguns valores construídos em sites de rede social que se relacionam diretamente com as categorias propostas por Bertolini e Bravo ${ }^{8}$.

A legitimação se refere ao reconhecimento da presença do outro na rede. O suporte social corresponde ao apoio, à construção de sentimento e à intimidade características dos laços fortes ${ }^{2}$. A visibilidade pode ser compreendida como a capacidade que tem um determinado ator de se fazer percebido por outros atores em uma rede. A popularidade é uma medida quantitativa relativa ao número de conexões estabelecidas por um ator e também em relação à sua posição na rede. A reputação é compreendida como a percepção construída sobre um determinado ator por outros atores. Por fim, a autoridade diz respeito à influência de um ator na rede social e também compreende a reputação, mas não se limita a ela. Uma vez construída a autoridade, um determinado nó poderia exercer influência sobre os demais nós de sua rede7.

A transposição das categorias mencionadas acima para os estudos de comunicação pode ser conferida nos trabalhos de Montardo e Silva ${ }^{9,10}$, Recuero ${ }^{11,12}$ e Recuero e Zago ${ }^{13,14}$ sobre a relação entre a formação do capital social e o uso de mídias sociais como os blogs, os fotologs, o Filmow, o Orkut e o Twitter. 


\section{Metodologia}

O objeto de estudo foi analisado com o aporte de uma ferramenta metodológica que propõe a construção do conhecimento teórico a partir de dados empíricos e tem sido indicada por pesquisadores brasileiros e estrangeiros para o estudo das mídias sociais e das redes sociais na internet. As técnicas propostas pela teoria fundamentada permitem identificar as ações dos sujeitos e as formas de capital social que são construídas no ambiente digital por meio da análise e da codificação dos comentários publicados nas mídias sociais. Além disso, Fragoso, Recuero e Amaral ${ }^{15}$ acreditam que o uso do método é interessante em um campo onde existe uma riqueza de dados disponíveis para coleta e um corpo teórico em desenvolvimento.

O campo escolhido para a realização do estudo foi um canal de divulgação científica sobre psicologia do YouTube. O canal Minutos Psíquicos foi criado em 2014 e contava com 758 mil usuários inscritos e 28.521.045 visualizações em 24 de novembro de 2019. Os vídeos publicados semanalmente abordam temas de interesse geral relacionados à psicologia, à ciência e ao comportamento humano com uma linguagem clara e acessível ao público leigo.

O canal Minutos Psíquicos faz parte da rede de canais de divulgação científica Science Vlogs Brasil (SVBr). Além de se constituir como uma rede de ajuda mútua e comunicação permanente, o SVBr é um selo de qualidade para divulgadores científicos que busca garantir que os vídeos publicados pelos canais associados estejam veiculando informações científicas sérias, com fontes certificadas, que representem o consenso científico e acadêmico corrente e sejam constantemente avaliadas pelos pares ${ }^{16}$. Desse modo, a participação na rede SVBr foi um critério importante para a seleção do canal. A escolha do canal também foi motivada pelo número de comentários e interações dos usuários. Partindo-se do pressuposto de que o capital social é construído a partir das interações entre os indivíduos, buscou-se um ambiente de conversação digital que possibilitasse a emergência dessa espécie de valor por meio do engajamento dos usuários com o conteúdo publicado.

As principais fontes de dados usadas nesse estudo foram o vídeo mais popular do canal Minutos Psíquicos no mês de abril de 2017, no que diz respeito às visualizações, aos comentários associados ao vídeo e aos memorandos elaborados durante a pesquisa. A coleta e a organização dos dados foram realizadas em 13 de julho de 2017 com suporte do software de análise de dados qualitativos NVivo. Na data da coleta, o vídeo contava com 817.643 visualizações, 2.064 comentários, 33.672 likes e 178 dislikes. Embora o vídeo apresentasse o número de comentários mencionado acima na ocasião da coleta, o NVivo conseguiu capturar apenas 1.183 deles por conta das restrições da plataformai. Dessa forma, o corpus final da pesquisa foi formado pelo vídeo Depressão e por 1.183 comentários a ele relacionados, além dos memorandos.

$\mathrm{Na}$ teoria fundamentada, os processos de coleta e análise de dados ocorrem concomitantemente. A análise teve início com a escolha do canal Minutos Psíquicos e do vídeo Depressão. Inicialmente, foram examinados o perfil do canal, o número de usuários inscritos e de visualizações e o seu engajamento com o conteúdo. Após a seleção do vídeo, foram analisados aspectos extrínsecos ao vídeo, como o número de visualizações, curtidas e comentários. A análise seguiu com a transcrição do conteúdo do vídeo Depressão e completou-se com a codificação dos comentários dos usuários.

Para a análise dos comentários, foram utilizadas as três técnicas de codificação da teoria fundamentada: aberta, axial e seletiva. Na codificação aberta foram identificadas e rotuladas as principais ações, interações e fenômenos emergentes nos comentários relacionados ao vídeo e nas conversações estabelecidas entre os usuários. A codificação axial permitiu agrupar os conceitos identificados em grandes categorias a partir das suas relações. Finalmente, na codificação seletiva, os conceitos e categorias emergentes foram integrados e confrontados com a literatura que deu sustentação ao trabalho.

O YouTube define o número que pode ser capturado pelo software e ele pode variar de acordo com a quantidade disponível. No caso dos vídeos mais populares e, portanto, com diversos comentários, só é possível capturar os mais recentes ${ }^{17}$. 


\section{Discussão dos dados}

A partir da leitura, interpretação e codificação dos comentários relativos ao vídeo Depressão, foram estabelecidas três categorias centrais e 23 subcategorias que representam as práticas discursivas observadas no contexto de estudo e contribuem direta ou indiretamente para a formação do capital social e de valores a ele relacionados. As categorias principiais e subcategorias associadas são apresentadas no Quadro 1.

Quadro 1 - Categorias e subcategorias identificadas no estudo

\begin{tabular}{|l|l|}
\hline CATEGORIA & SUBCATEGORIAS \\
\hline & Afabilidade \\
& Aprovação \\
& Autopercepção \\
& Causas e consequências \\
& Comicidade \\
& Críticas \\
& Desaprovação \\
Autoexpressão & Dúvidas \\
& Estratégias \\
& Experiências \\
& Identificação \\
& Informações de contato \\
& Opinião \\
& Pedidos de ajuda \\
& Provocação \\
& Reações ao vídeo \\
\hline Reações do canal & Aconselhamento \\
& Esclarecimento \\
\hline Suporte social & Mensagens de apoio \\
& Prestação de ajuda \\
& Recomendações \\
\hline
\end{tabular}

Fonte: Elaborado pelos autores (2018).

A categoria autoexpressão compreende as subcategorias: afabilidade, aprovação, autopercepção, causas e consequências, comicidade, críticas, desaprovação, dúvidas, estratégias, experiências, identificação, informações de contato, opinião, pedidos de ajuda, provocação e reações ao vídeo. O teor dos comentários classificados nessa categoria indica uma forte evidência da presença de confiança no ambiente social na medida em que os usuários não demonstram qualquer preocupação com a privacidade das informações compartilhadas no contexto investigado. Para Bertolotti e Medeiros ${ }^{18}$, "a facilidade para a produção e divulgação de conteúdos, bem como a ideia (nem sempre verdadeira) de segurança para a autoexposição, transformaram a internet e, de maneira especial, o YouTube, em território percebido como seguro para a livre expressão, tanto por youtubers quanto por viewers (espectadores no contexto da internet)".

A aparente falta de cuidado em relação à exposição da intimidade pode ser considerada o 'preço a pagar' pelos benefícios que a publicação de informações pessoais pode trazer. Em outros termos, a 'expressão de si’ revela não só a confiança no ambiente social, mas se configura como uma espécie de investimento para a obtenção de valores de capital social.

A subcategoria autopercepção constitui a principal prática discursiva identificada nos comentários analisados. Cerca da metade deles enquadra-se nessa subcategoria, o que indica a sua importância no contexto do estudo. Em geral, as mensagens codificadas em autopercepção expressam sentimentos, 
pensamentos, desejos, angústias e motivações dos usuários em relação a si próprios, aos outros e às situações vivenciadas. Muitos usuários afirmam ter depressão e descrevem a forma como a sentem, os pensamentos que lhes ocorrem, quais os impactos do problema em sua vida e o que esperam do futuro.

As mensagens de autopercepção podem ser vistas como uma forma de capital social cognitivo na medida em que representam um conjunto de significados ou conhecimentos compartilhados pelos usuários que estão disponíveis para acesso e uso. A palavra compartilhamento é entendida, aqui, tanto como o ato de disponibilizar um determinado recurso pessoal para a coletividade como no sentido de uma construção de significados comuns a um grupo de pessoas. Na realidade, esses dois aspectos estão diretamente relacionados e contribuem para a formação de um conhecimento coletivo naquele ambiente informacional específico. Esse conhecimento, embora baseado na experiência individual, torna-se um valor que pode ser usufruído por todos os interessados.

Outra subcategoria que merece destaque pela expressividade de comentários é a subcategoria experiências, que inclui mensagens nas quais os usuários contam fatos de sua vida relacionados à depressão, compartilham informações de caráter biográfico, informam há quanto tempo convivem com o problema, relatam que medidas foram tomadas para procurar ajuda e se os resultados foram satisfatórios, bem como descrevem situações do passado que tiveram impacto em sua vida. Resultado semelhante foi encontrado no trabalho realizado por Caran e Biolchini ${ }^{19}$ sobre o suporte social informacional no grupo Low Vision do Facebook. A categoria experiência de vida, representada por "relatos ou solicitações de depoimentos sobre situações específicas, sentimentos ou circunstâncias vividas pelo indivíduo", aparece em segundo lugar, em número de publicações, entre as 16 categorias identificadas no estudo. Segundo os autores, foi encontrado um número significativo de usuários que se apresentam e relatam experiências de vida com o objetivo de receber comentários de outros que se encontram na mesma condição.

As mensagens codificadas como causas e consequências consistem em relatos nos quais os usuários apontam os possíveis fatores que desencadearam o problema enfrentado, além dos prejuízos causados pela depressão nas diferentes áreas da vida. Diversos comentários estabelecem uma relação direta entre experiências que foram marcantes para os usuários e a situação atual. São relatadas situações vivenciadas com amigos, familiares, parceiros afetivos e colegas de escola, que segundo esses usuários podem ter sido a causa da depressão.

Como afirmado em relação aos comentários de autopercepção, as mensagens codificadas como 'causas e consequências' também parecem ter o intuito de construir um significado ou uma explicação para as situações vivenciadas. Nesse sentido, o conteúdo do vídeo tende a contribuir para o exercício de autorreflexão e autoconhecimento dos usuários, além de oferecer um contexto no qual eles podem expressar suas ideias e opiniões e, de certa forma, obter a legitimação do seu discurso. Em outras palavras, o espaço de comentários do vídeo funciona como um lugar onde os usuários têm a liberdade para compartilhar aquilo que pensam sobre si mesmos sem passar algum tipo de censura ou pelo julgamento de uma autoridade externa.

Nos comentários sobre o vídeo Depressão, os usuários mencionam diversas estratégias usadas para lidar com o problema. Alguns relatam que fizeram uso de medicação após procurar ajuda de profissionais da psicologia, psiquiatria e neurologia e receber o diagnóstico da doença. Porém, as queixas de que a medicação não teve o efeito esperado são frequentes. Outros usuários buscaram ajuda na religião e afirmam que alcançaram a cura para a doença através da fé. Há ainda aqueles que sentiram melhoras após desabafar com a família e os amigos. Também é possível observar que alguns usuários desenvolveram maneiras próprias para lidar com o problema, tais como: escrever histórias, desenhar, jogar videogame, compor letras de músicas, cantar, pesquisar e estudar sobre o assunto, ler livros e artigos sobre o tema, realizar trabalho voluntário, fazer atividade física, contar piadas, fortalecer a autoestima, pensar positivamente, entre outras.

Por outro lado, muitos usuários argumentam que não procuraram ajuda por algumas razões, como: não ter dinheiro para manter o tratamento, a dificuldade para conseguir atendimento na rede pública e 
encontrar planos de saúde acessíveis, o medo de ser julgado pelas outras pessoas, o fato de não acreditar no tratamento, a vergonha de contar para os pais e o receio de incomodar ou causar sofrimento à família. Os comentários codificados como estratégias podem se tornar informações valiosas àqueles usuários que buscam soluções para os seus problemas e, dessa forma, funcionariam como capital social cognitivo. Observa-se, contudo, que volume de comentários codificados na subcategoria estratégias é significativamente menor do que aquele categorizado em autopercepção, ou seja, são poucos os usuários que demonstram em seus relatos ter a consciência de que é necessário buscar ajuda para enfrentar a depressão. O conteúdo do vídeo desempenha um papel importante no esclarecimento dos usuários, uma vez que explica que as principais causas para a alta prevalência da depressão no mundo inteiro são o preconceito e o receio de buscar ajuda profissional.

Um elemento que aparece bastante no discurso dos usuários é a crítica ao modo como outras pessoas, em geral familiares, enxergam o problema pelo qual estão passando, isto é, a depressão. A queixa fundamental de grande parte dos usuários é de que as pessoas do seu entorno não levam a depressão a sério. São comuns os comentários afirmando que depressão não é frescura. Desse modo, a subcategoria críticas foi criada para reunir mensagens que demonstram a insatisfação dos usuários em relação à maneira como os amigos, familiares e a sociedade, de modo geral, lidam com as pessoas que enfrentam a doença.

Embora o volume de comentários codificados na subcategoria críticas não seja tão expressivo como o classificado em autopercepção, essas mensagens oferecem pistas sobre as motivações dos usuários que publicam seus relatos no canal. Uma possível explicação para o uso desse espaço visando ao desabafo seria a ausência de uma rede de relações sociais no plano offline que ofereça o suporte necessário a esses usuários para lidarem com os problemas que experienciam. Considerando que uma das características da comunicação mediada pelo computador é a ausência ou redução dos constrangimentos que a comunicação face a face pode promover, é possível que pareça mais fácil a esses indivíduos exporem seus problemas para uma audiência difusa, mas que possui características em comum, do que para pessoas de suas relações sociais que não compreendem o problema. Desse modo, pode-se afirmar que as mensagens codificadas na categoria críticas têm um forte apelo relacional, isto é, permite a aproximação entre indivíduos por meio do aprofundamento dos laços sociais e da construção de capital social relacional7 7 .

A subcategoria dúvidas reúne comentários nos quais os usuários apresentam questões sobre o tema abordado no vídeo ou outros assuntos de interesse. É nessa subcategoria que o intercâmbio de informações fica mais evidente. Mensagens do tipo "como foi a sua experiência com o psicólogo? Positiva, negativa?" (comentário 234) ou "tem alguma ajuda pública ou gratuita para depressão?” (comentário 351) são exemplos de dúvidas apresentadas pelos usuários. Embora o contexto do estudo possa ser considerado rico em capital social cognitivo (informação e conhecimento compartilhado), pode-se observar que o ato de buscar informações com outros usuários do canal não é muito expressivo. Segundo Wellman e $\mathrm{Gulia}^{20}$, a informação é apenas um dos recursos trocados no ambiente virtual. Muitos usuários da internet obtêm ajuda em grupos eletrônicos para problemas sociais, físicos e mentais, além de informações sobre tratamentos, profissionais e outros recursos. Tais práticas foram observadas no estudo de Frohlich e Zmyslinski-Seelig ${ }^{21}$ sobre os tipos de mensagens de suporte social publicadas por usuários, em vídeos do YouTube, sobre doenças inflamatórias intestinais e ostomia. Os resultados apontaram que as mensagens de suporte informacional foram as mais frequentes $(65,1 \%)$, seguidas de mensagens de suporte emocional $(18,3 \%)$ e de mensagens de suporte instrumental $(8,2 \%)$.

Outro comportamento típico no contexto de estudo foram os pedidos de ajuda. Nessa subcategoria foram codificados os comentários nos quais os usuários demonstram, explicitamente, que estão passando por um momento difícil e necessitam de apoio. Alguns usuários parecem ter chegado ao seu limite e não podem contar com o suporte de pessoas próximas para resolver o problema. O comentário 193 ilustra esse tipo de comportamento: "Já faz um ano que sofro com isso. Pensei que fosse algo passageiro, mas esse ano só piorou. 
Tenho muita vontade de me matar. Tento gritar mas ninguém me escuta, preciso de ajuda”. Um comportamento semelhante foi identificado no estudo realizado por Recuero ${ }^{11}$ sobre o capital social no Orkut e nos weblogs. Segundo a autora, a existência de pedidos de suporte sugere uma expectativa por parte do usuário em relação ao comportamento dos outros membros do grupo. Nesse caso, os blogueiros que apresentaram pedidos de ajuda acreditavam que seriam compreendidos e que os demais reagiriam de uma determinada maneira. Além de indicar que os usuários buscam o suporte social por meio de suas interações no ambiente digital, esse comportamento revela a existência de outra forma de capital social: a confiança no ambiente social.

Para Bertolini e Bravo ${ }^{8}$, um alto nível de confiança no ambiente social promove a redução da incerteza em relação às ações dos componentes de um grupo. A confiança também oferece maior tranquilidade para o estabelecimento de interações entre os indivíduos ${ }^{2}$. Nesse sentido, pode-se considerar que a confiança é um valor percebido pelos usuários que publicaram seus comentários, o que contribui para que se sintam seguros para pedir ajuda naquele contexto. A presença da confiança no ambiente de estudo pode estar relacionada ao fato de que boa parte dos autores dos comentários acredita estar passando pelo problema da depressão, ou seja, há uma certa identificação entre esses usuários. Essa suposição pode ser confirmada na subcategoria identificação.

Os comentários codificados como identificação são muitas vezes respostas aos comentários de autopercepção nas quais os usuários demonstram que se identificaram com as situações vivenciadas pelos demais. No comentário 1.09o, esse comportamento fica explícito: "Colega, saiba que você não é o único que passa por isso". Pode-se observar também que a identificação é capaz de gerar empatia e, consequentemente, aproximar indivíduos que passam pelo mesmo problema.

A busca pelo estabelecimento de laços sociais é um aspecto que aparece nas mensagens codificadas como informações de contato. São diversos os comentários que trazem o número de telefone dos usuários para contato via WhatsApp. O comentário 134 consiste em uma dessas tentativas de estabelecer contato: "Vou criar um grupo no whatsapp, então quem quiser entrar deixa o número aí nos comentários Vlw". Outras ferramentas de comunicação também foram mencionadas, como e-mail, Facebook, Hangouts e Google+. Segundo Recuero7, os laços sociais mediados pelo computador costumam ser multiplexos, isto é, refletem interações que acontecem em diferentes espaços e sistemas. O comentário 36 é um exemplo de que as interações estabelecidas entre os usuários podem extrapolar os limites do YouTube: "esquece que eu existo, $e$ vou trocar de número".

Os comentários codificados na subcategoria informações de contato revelam o desejo dos usuários de estabelecer interações sociais e, ao mesmo tempo, a confiança no ambiente social. Também é possível notar que boa parte dos usuários que fornecem seus contatos está buscando alguém para desabafar ou quer oferecer ajuda. Sendo assim, pode-se considerar que essas mensagens são indícios da presença de capital social relacional, confiança no ambiente social e suporte social.

Os comentários codificados na subcategoria aprovação, em geral, são mais sucintos e demonstram concordância com o discurso do outro. De certo modo, essas mensagens atuam no sentido de legitimar uma determinada opinião ou forma de pensar. De acordo com Recuero ${ }^{2}$, a criação e a manutenção de um perfil em sites de redes sociais podem promover a legitimação desse investimento, ou seja, o reconhecimento da presença de um determinado indivíduo naquele contexto. Contudo, os resultados do estudo sugerem que a legitimação, compreendida como uma forma de capital social, pode ser obtida não só por meio da criação de um perfil em uma plataforma de mídia social, mas também quando os usuários expressam seus pensamentos e opiniões nesses espaços, como no contexto do estudo, por exemplo. A ocorrência dessa prática também foi identificada no trabalho conduzido por Rodrigues, Silva e Barros ${ }^{22}$, que abordou os tipos de interações estabelecidas em dois canais educacionais do YouTube na área das ciências naturais: Ted-Ed e o AsapSCIENCE. O estudo revelou que os comentários questionando, concordando e cumprimentando 
outros usuários, representados pela categoria Utilizadores, estavam presentes em quatro dos seis vídeos analisados pelos autores.

Outra manifestação considerada positiva no contexto do estudo foi a afabilidade. Os comentários codificados nessa subcategoria representam relações de afeto, educação, respeito e simpatia entre os usuários. O comentário 757 é um exemplo dessa forma de comportamento: "leio os comentários, e me dá uma vontade enorme de abraçar todos vcs que se sentem assim". Pelo teor desse comentário, pode-se perceber que o ambiente do vídeo é propício para a realização de trocas afetivas. Essas manifestações têm o potencial de promover o estreitamento dos laços ou, em outras palavras, a construção do capital social relacional.

Na subcategoria comicidade foram codificados os comentários nos quais os usuários têm a intenção de provocar o riso ou demonstram terem achado algo engraçado. Um exemplo dessa subcategoria é o comentário 215, no qual o usuário reage ao comentário de outro: "kkkkkkkkkkkk só assim pra eu rir em meio às lágrimas". No entanto, essas mensagens podem ter um caráter depreciativo, como é o caso do comentário 216: "KKKK.....seu comentário me curou!". Os comentários da subcategoria comicidade podem, assim, ser interpretados de maneira positiva ou negativa dependendo do contexto e da intenção do usuário. Segundo Recuero ${ }^{23}$, nos sites de redes sociais, a prática de 'trolling' ou 'trollagem' parece bastante associada com o humor e tem por objetivo principal desestabilizar a face ${ }^{\mathrm{ii}}$ alheia, ou seja, a imagem positiva construída por um determinado indivíduo diante dos demais. Um exemplo dessa prática é a propagação de 'memes' com o intuito de ridicularizar ou comprometer a imagem de indivíduos ou grupos de indivíduos no ambiente digital. Com esse comportamento, os chamados 'trolls' buscam a visibilidade por meio do humor e da desestabilização da face do outro.

A subcategoria opinião inclui comentários que expressam o modo de pensar dos usuários acerca da depressão, bem como sobre os problemas enfrentados por outros usuários. O comentário 519 tem caráter opinativo e a intenção de orientar um usuário que demonstra estar em situação de desespero: "Não é frescura. Assim que puder, busque um profissional". Já o comentário 1.048 apresenta uma opinião crítica sobre o comportamento de algumas pessoas que passam pelo problema: "Não sei como tem gente que usa a depressão para chamar a atenção na internet". Os dois comentários acima mostram que as opiniões compartilhadas no espaço do vídeo podem ter intencionalidades distintas. Em alguns casos, podem contribuir para ajudar os usuários a enfrentarem o problema e, em outros, podem causar o efeito contrário. No entanto, esses efeitos só podem ser verificados por meio de uma intervenção direta do pesquisador.

A subcategoria provocação é composta por mensagens que trazem conteúdo agressivo ou até mesmo ofensivo aos outros usuários. Um dos comentários classificados nessa subcategoria desencadeou 27 respostas, configurando-se como uma das interações mais extensas do corpus. No comentário 139, o usuário afirma que a "depressão virou moda". Embora o comentário seja sucinto em relação a outros que geraram diversas reações, houve uma série de respostas criticando a opinião desse usuário. Apenas uma pessoa ponderou que "ele apenas falou que algumas pessoas fingem ter depressão..." (comentário 154). Além de indicar uma forma de comportamento social, a interação gerada pelo comentário 139 é um bom exemplo da presença do capital social normativo no contexto estudado. De certa forma, o autor do comentário parece subestimar o problema apresentado pelos usuários que se expressam por meio dos comentários. A reação negativa dos outros usuários vem no sentido de inibir esse tipo de comportamento contrário aos valores do grupo e pode atuar como uma espécie de controle social, na medida em que permite que seja mantida a ordem dentro do grupo. Para Bertolini e Bravo ${ }^{8}$, a existência do capital social normativo (capital social de primeiro nível), ou seja, de normas e valores internalizados, pode contribuir para aumentar a confiança no ambiente social (capital social de segundo nível) e nas ações dos outros indivíduos. Desse modo, a presença

ii O conceito de face foi proposto pelo sociólogo canadense Erving Goffman na obra Interaction ritual: essays on face-to-face behavior, publicada originalmente em 1967. 
do capital social normativo garante que os usuários sintam-se à vontade para compartilhar informações sobre si sem serem julgados.

As estratégias de ataque e defesa da face (compreendida como a imagem construída pelo indivíduo em sociedade), com a utilização da polidez e da impolidez na linguagem, foram abordadas por Quaresma ${ }^{24}$. A autora analisou as interações dos usuários do YouTube em relação a uma campanha publicitária de perfumes para o dia dos namorados, veiculada em 2015 pela empresa O Boticário, que incluía casais homoafetivos. Entre os atos de impolidez identificados no estudo, constatou-se a predominância de atos ameaçadores de face diretos e livres de atenuadores. Ao se depararem com argumentos contrários aos seus valores morais e crenças, alguns usuários mostraram-se agressivos, disparando insultos às faces do anunciante e dos demais usuários. Por outro lado, também foram identificadas nos comentários estratégias de polidez, usadas com o intuito de suavizar a linguagem nos atos de fala.

Como apontado anteriormente, alguns comentários têm o objetivo de tolher comportamentos considerados inapropriados. Essas mensagens foram codificadas neste estudo na subcategoria desaprovação. Porém, nem sempre os comentários de desaprovação são realizados em reação a mensagens de tom agressivo. O comentário 321 foi publicado em resposta ao depoimento de um usuário que afirma pensar em suicídio 24 horas por dia: "imagina quem está nesse momento sem ter o que comer e sem dinheiro ou sem teto, ou na uti ou na cti onde tem pessoas entre a vida e a morte que nesse exato momento pedem a Deus pra viver, pense nisso e não pensará em morrer". Os argumentos usados pelo autor do comentário têm o intuito de reprovar a atitude do outro usuário e conscientizá-lo sobre outros problemas que afetam a sociedade. Nesses casos, as mensagens de desaprovação podem funcionar como uma forma de suporte social na medida em que buscam ajudar os usuários a lidar com situações difíceis.

A última subcategoria da categoria autoexpressão corresponde às reações ao vídeo. De modo geral, a subcategoria reações ao vídeo reúne comentários dirigidos ao canal. As mensagens codificadas nessa subcategoria compreendem elogios, críticas, dúvidas, depoimentos, agradecimentos ao canal, demonstrações de identificação com o vídeo, sugestões de temas a serem abordados e relatos de inscrições no canal. Em sua maioria, esses comentários são positivos, os usuários expressam gratidão pelo conteúdo compartilhado, relatam que foram ajudados pelo canal, tiram suas dúvidas em relação ao vídeo e parabenizam o canal pela qualidade do conteúdo. Um exemplo desse comportamento pode ser visualizado no comentário 274: "Primeiramente quero agradecer ao canal, por ter feito um vídeo q me fez decidir o q quero fazer da minha vida... continuem fazendo vídeos assim, Deus abençoe vcs!!”. Entretanto, alguns usuários apresentam críticas tanto em relação ao conteúdo como à forma de apresentá-lo. No comentário 257, o usuário faz a seguinte afirmação em relação às ilustrações apresentadas nos vídeos do canal: "o desenho me distrai". Em seguida, outros usuários publicaram comentários discordando ou concordando com essa opinião. Nesse caso, o canal não se manifestou, mas em outros comentários é possível perceber a sua intervenção.

As reações aos vídeos também foram observadas em outros trabalhos realizados no YouTube. Guedes e Nicolau ${ }^{25}$ estudaram a apropriação e o compartilhamento de videoclipes interativos na plataforma. Na análise dos comentários em videoclipes da música We used to wait, da banda Arcade Fire, compartilhados por usuários, os autores encontraram relatos sobre experiências com o conteúdo, elogios em relação ao caráter inovador do produto, o reconhecimento de cenários em outras experiências interativas compartilhadas, a descrição de problemas na execução do vídeo e a busca de soluções para os problemas apresentados. Em seu estudo sobre a representatividade Queer em tutoriais de maquiagem do YouTube, Bertolotti e Medeiros ${ }^{18}$ analisaram um dos vídeos mais populares do maquiador, youtuber e digital influencer Antonio Campagna. Segundo as autoras, os comentários em seus vídeos demonstram grande apreço por parte dos usuários, que o incentivam à publicação de novos vídeos e apresentam elogios às maquiagens que realiza, à sua desenvoltura, à forma como cativa seus seguidores e à sua simpatia e simplicidade. Embora o foco desses estudos tenha sido bastante específico, nota-se que a prática de interagir com os conteúdos também 
pode ser vista em outros contextos do YouTube e que o teor dos comentários pode variar de acordo com as características do material publicado, bem como com o perfil dos produtores.

A segunda categoria identificada na análise compreende as reações do canal Minutos Psíquicos aos comentários sobre o vídeo e está subdividida em: orientação e resposta emocional. Embora seja pouco expressiva em termos quantitativos, essa categoria se diferencia das categorias autoexpressão e suporte social por representar o comportamento do canal e não dos usuários. Dessa forma, houve necessidade de criá-la a fim de agrupar as respostas dele provenientes. Na subcategoria 'orientação', foram reunidas aquelas mensagens nas quais o canal oferece sugestões aos usuários que relatam estar passando pela depressão. Em geral, a sua recomendação é que os usuários procurem ajuda profissional e indica um vídeo explicando como buscar ajuda psicológica. No comentário 30, o canal responde a um usuário que demonstra insatisfação com o tratamento medicamentoso: "Infelizmente, o uso exclusivo de medicação é a opção de alguns profissionais de saúde e não ajuda tanto assim o paciente a melhorar a longo prazo depois que a medicação é interrompida. Por isso geralmente é recomendável que a medicação seja acompanhada também da psicoterapia".

Além de mostrar o posicionamento do canal em relação ao assunto, o comentário acima parece ter o intuito de esclarecer o usuário quanto à eficácia das distintas modalidades de tratamento para a depressão. De certo modo, a afirmação está de acordo com a informação fornecida no vídeo de que a medicação pode atuar como um recurso auxiliar para a diminuição dos sintomas da doença. Neste sentido, as orientações oferecidas pelo canal funcionam como suporte social aos usuários que expõem o seu problema naquele espaço e como uma espécie de capital cognitivo que pode ser útil na tomada de decisão relativa à situação enfrentada. A presença do capital social cognitivo, na forma de acesso a informações e conhecimentos compartilhados, também foi verificada nos estudos realizados por Montardo e Silva ${ }^{9,10}$, Recuero ${ }^{11}$ e Recuero e Zago ${ }^{13,14}$.

Os comentários classificados como resposta emocional são, em sua maioria, mensagens de agradecimento pelos elogios, sugestões e depoimentos recebidos pelo canal nos quais os usuários informam que foram ajudados por meio do conteúdo publicado. Essas mensagens indicam que houve uma troca afetiva entre os usuários e o canal e um interesse verdadeiro desse último pelas contribuições dos primeiros. O comentário 256 é um exemplo de resposta emocional do canal Minutos Psíquicos ao depoimento de um usuário: "poxa, que ótimo! Fico feliz mesmo que o canal tenha te ajudado de alguma forma! Muito obrigado por compartilhar isso com a gente ;)".

Por fim, a terceira categoria identificada na análise dos dados foi rotulada como suporte social e está subdividida em aconselhamento, esclarecimento, mensagens de apoio, prestação de ajuda e recomendações. As mensagens codificadas nessas subcategorias representam demonstrações explícitas de suporte aos usuários que compartilham suas experiências com a depressão nos comentários do vídeo. Segundo Recuero $^{2}$, as conexões emergentes nos sites de redes sociais e, por extensão, em outras plataformas de mídia social, podem trazer benefícios aos usuários como o suporte social e a legitimação da presença. No entanto, o acesso a essas formas de capital social é resultado do trabalho de investimento na criação e na manutenção de conexões sociais. Em relação ao contexto do estudo, é possível notar que o investimento nas conexões emergentes aparece de forma bastante clara nas mensagens codificadas como suporte social.

A subcategoria aconselhamento reúne comentários nos quais são apresentadas diversas opções para a resolução dos problemas relatados. Boa parte dos usuários recomenda a ajuda profissional como a melhor alternativa para os casos de depressão. O comentário 63 representa essa forma de aconselhamento: "Só você sabe o que passa. Procure um profissional da área. Depressão tem cura e você precisa de ajuda". Outros usuários acreditam que o recurso mais efetivo para superar o problema é a fé ou a religião, como fica explicitado no comentário 376: "jesus é seu melhor amigo!!! se vc acredita nele é melhor ainda!!! conversa bastante com ele e sua vida vai mudar muito!! n tenha vergonha". Também foram identificados comentários que buscam conscientizar os usuários de que existem formas alternativas de resolver o problema. No comentário 
1.142, algumas possibilidades são sugeridas: "[...] tenta arranjar algo que você goste e se sinta bem (dançar, jogar, fazer exercícios, escrever, ler...)”. As sugestões apresentadas na subcategoria aconselhamento, além de representarem uma forma de suporte social, podem ser vistas como capital social cognitivo, ou seja, um conjunto de informações que pode ser utilizado pelos usuários para atingir os seus objetivos.

Os comentários codificados na subcategoria esclarecimento foram pouco expressivos e têm o objetivo de responder às dúvidas apresentadas pelos usuários. Do mesmo modo que a subcategoria aconselhamento, as mensagens de esclarecimento fornecem ao mesmo tempo suporte social e informação. Nesses comentários, o intercâmbio de informações pode ser visualizado de maneira mais concreta. No comentário 239, o usuário faz um alerta sobre o uso de cannabis para o tratamento da depressão: "cuidado cara, o correto seria usar algum medicamento específico, os níveis de the podem até agravar quadros depressivos e de ansiedade". O comentário 239 é um exemplo de conhecimento compartilhado com o grupo e, portanto, corresponde ao capital social cognitivo. Essa forma de comportamento também foi observada no estudo desenvolvido por Corrêa e Rozados ${ }^{26}$. Os autores constataram que um dos participantes da comunidade estudada costumava compartilhar os seus conhecimentos com aqueles usuários que apresentavam dúvidas ao grupo. De certo modo, esses indivíduos estão construindo um capital social cognitivo que pode ser usufruído por outros até que as mensagens sejam apagadas.

A subcategoria mensagens de apoio é formada por comentários que trazem mensagens de otimismo e mostram empatia entre os usuários que convivem com a depressão. Não são apresentadas sugestões para a resolução do problema, como em aconselhamento, nem sequer oferecimento de uma ajuda efetiva, como em prestação de ajuda. No entanto, são mensagens que trazem um conteúdo afetivo importante e expressam solidariedade e preocupação. No comentário 455, esse comportamento pode ser observado: “Um dia tudo passa, ninguém veio ao mundo apenas pra sofrer. E um dia vc vai ser tão feliz na vida, que vai parar pra pensar 'e se eu tivesse morrido?'... E vai agradecer por estar vivo!'. Nessas mensagens, a intenção de oferecer suporte social é perceptível. Conforme explica Recuero², o suporte social é um benefício individual que pode ser obtido por meio de conexões emergentes. Neste sentido, as interações estabelecidas entre os usuários são fundamentais para que esse valor possa emergir em um determinado contexto.

Embora as mensagens de apoio e de aconselhamento representem formas de prestar ajuda, a subcategoria prestação de ajuda é composta por comentários nos quais os usuários oferecem suporte, de maneira explícita, aos usuários que compartilharam seus problemas no espaço de comentários do vídeo. Em geral, os usuários se colocam à disposição para conversar e fornecem informações de contato. Observa-se nesses comentários que existe um interesse efetivo por parte de alguns usuários em ajudar os demais. O comentário 198 traz um exemplo dessa forma de comportamento: "Vou criar um grupo no whats para trocarmos experiências, ideias e nos ajudarmos. Quem quiser participar, deixa o contato que eu add. Abraço em todos e lembrem-se que o isolamento é o alimento da depressão". As mensagens codificadas nessa subcategoria são indícios de que o espaço do vídeo está sendo utilizado para a construção do capital social relacional, do suporte social e da confiança no ambiente social. O comentário 198 também indica a possibilidade de formação de um grupo de pessoas com depressão, o que poderia contribuir para a construção do capital social institucional.

A última subcategoria de suporte social diz respeito às recomendações dos usuários. Os comentários codificados nessa subcategoria trazem diversas indicações de vídeos e canais do YouTube, jogos, literatura, serviços de atendimento e uma loja virtual. As mensagens servem para divulgar esses recursos como uma forma de ajudar os usuários que passam pela depressão. No comentário 1.079, é possível visualizar um exemplo de comentário codificado nessa subcategoria: "Se vc está sob depressão, conheça a South América Memes. O humor curou-me". O South América Memes consiste em um canal do YouTube do gênero humor que faz a remixagem de conteúdos gerados pelos usuários e de conteúdos produzidos pela mídia tradicional. No estudo de Caran e Biolchini ${ }^{19}$, mencionado anteriormente, a categoria Livro, Revista e Website, descrita como "indicações de livros, revistas ou páginas web com temas voltados para o deficiente visual ou profissionais 
de saúde", figura em oitavo lugar entre as 16 categorias encontradas na análise. Em ambos os casos, as mensagens codificadas como recomendações podem funcionar como suporte social e capital cognitivo, o que comprova que o capital social é um conceito multifacetado ${ }^{8}$.

No Quadro 2, são apresentadas de maneira esquematizada as práticas discursivas verificadas no contexto do estudo (subcategorias e categorias), bem como algumas formas e os valores de capital social propostos por Bertolini e Bravo $^{8}$ e Recuero ${ }^{7,2}$. É importante salientar que as subcategorias e categorias apresentadas na primeira e segunda coluna emergiram a partir da realidade empírica e são consideradas formas de investimento na construção do capital social, enquanto as formas e valores elencados na terceira coluna correspondem ao capital social gerado a partir de tais práticas.

Quadro 2 - Práticas discursivas e formas e valores de capital social

\begin{tabular}{|c|c|c|}
\hline SUBCATEGORIAS & CATEGORIAS & CAPITAL SOCIAL \\
\hline $\begin{array}{l}\text { Afabilidade } \\
\text { Críticas } \\
\text { Identificação } \\
\text { Informações de contato } \\
\text { Prestação de ajuda } \\
\text { Resposta emocional }\end{array}$ & $\begin{array}{l}\text { Autoexpressão } \\
\text { Reações do canal } \\
\text { Suporte social }\end{array}$ & Capital social relacional \\
\hline $\begin{array}{l}\text { Aconselhamento } \\
\text { Autopercepção } \\
\text { Causas e consequências } \\
\text { Dúvidas } \\
\text { Esclarecimento } \\
\text { Estratégias } \\
\text { Orientação } \\
\text { Recomendações }\end{array}$ & $\begin{array}{l}\text { Autoexpressão } \\
\text { Reações do canal } \\
\text { Suporte social }\end{array}$ & Capital social cognitivo \\
\hline $\begin{array}{l}\text { Desaprovação } \\
\text { Provocação }\end{array}$ & Autoexpressão & Capital social normativo \\
\hline $\begin{array}{l}\text { Informações de contato } \\
\text { Pedidos de ajuda } \\
\text { Prestação de ajuda }\end{array}$ & Autoexpressão & Confiança no ambiente socia \\
\hline Aprovação & Autoexpressão & Legitimação \\
\hline $\begin{array}{l}\text { Aconselhamento } \\
\text { Críticas } \\
\text { Esclarecimento } \\
\text { Informações de contato } \\
\text { Mensagens de apoio } \\
\text { Opinião } \\
\text { Orientação } \\
\text { Pedidos de ajuda } \\
\text { Prestação de ajuda } \\
\text { Recomendações }\end{array}$ & $\begin{array}{l}\text { Autoexpressão } \\
\text { Reações do canal } \\
\text { Suporte social }\end{array}$ & Suporte social \\
\hline Comicidade & Autoexpressão & Visibilidade \\
\hline
\end{tabular}

Fonte: Elaborado pelos autores (2018).

Ao contrário do que se poderia pensar, o intercâmbio de informações não foi expressivo no contexto analisado. Embora o canal Minutos Psíquicos e, mais precisamente, o vídeo Depressão, possa ter contribuído para suscitar dúvidas aos usuários e levá-los a compartilhá-las em seus comentários, o intercâmbio de informações foi observado apenas nas subcategorias dúvidas e esclarecimento. Dessa forma, nota-se que o contexto do estudo foi mais usado para a construção de outras formas de capital social do que para a 
obtenção do capital social cognitivo, isto é, para a busca de informações. Por outro lado, o conteúdo do vídeo Depressão foi capaz de mobilizar os indivíduos a realizarem uma série de práticas sociais naquele ambiente que produziram resultados concretos em matéria de capital social.

\section{Considerações finais}

O estudo que fundamenta este artigo teve como objetivo analisar a relação entre o conteúdo publicado em um canal de divulgação científica do YouTube e a formação do capital social. No final do estudo, foram identificadas três categorias principais e 23 subcategorias a elas associadas que representam as práticas discursivas identificadas no contexto estudado e contribuem para a construção de determinadas formas e valores de capital social que podem ser usufruídos tanto individualmente como pelo grupo como um todo. Vale destacar que algumas categorias e subcategorias emergentes na análise parecem ser específicas do campo de estudo e talvez não se apliquem a outros contextos.

O capital social relacional aparece nas três categorias principais e, particularmente, nas subcategorias afabilidade, críticas, identificação, informações de contato, resposta emocional e prestação de ajuda. De certo modo, essas práticas sociais discursivas contribuem para o estabelecimento de relações entre os usuários e formação de laços sociais. Entretanto, a presença do capital social relacional é notada mais fortemente na categoria autoexpressão, o que pode sugerir uma relação entre o compartilhamento de conteúdos sobre si e a sociabilidade no ambiente digital.

O capital social cognitivo parece estar distribuído de maneira mais uniforme nas três principais categorias do estudo. É possível constatar sua presença nas subcategorias autopercepção, causas e consequências, dúvidas, estratégias, orientação, aconselhamento, esclarecimento e recomendações. Nas quatro primeiras subcategorias, o capital cognitivo parece surgir como resultado de um trabalho de autorreflexão dos usuários em relação às suas percepções, vivências e inquietações, ou seja, uma construção individual que é compartilhada com o exterior. Nas demais subcategorias, essa forma de capital surge em resposta aos relatos dos usuários sobre as situações vivenciadas, ou seja, é fruto de um investimento que gere o suporte informacional.

O capital social normativo aparece apenas na categoria autoexpressão e, mais precisamente, na subcategoria desaprovação. Essa subcategoria está diretamente relacionada com a subcategoria provocação, pois os comportamentos hostis costumam gerar reações de caráter normativo por parte dos usuários. Em outras palavras, quando um usuário faz um comentário com tom ofensivo, observa-se uma série de reações repreendendo essa atitude de modo que a harmonia entre os membros do grupo seja mantida. Tanto os casos de provocação como de desaprovação foram pouco expressivos no contexto do estudo.

A confiança no ambiente social pode ser percebida em todas as mensagens que compõem a categoria autoexpressão na medida em que elas possuem caráter extremamente pessoal. Porém, essa forma de capital social manifestou-se mais explicitamente nas subcategorias informações de contato, pedidos de ajuda e prestação de ajuda. Nesses casos, nota-se que os usuários não se importam se os seus interlocutores são desconhecidos. As informações de contato, como números de telefone, são compartilhadas sem nenhuma reserva e os pedidos de ajuda são dirigidos a qualquer pessoa. A principal motivação para esse comportamento talvez seja a vontade de ajudar e de ser ajudado.

O capital social institucional não aparece concretamente no contexto do estudo, porém são encontrados alguns indícios dessa espécie de valor. A presença do capital social relacional é um indicativo de que as relações sociais estabelecidas naquele espaço podem evoluir para a constituição de grupos com interesses comuns, nesse caso o tema da depressão, e acabar favorecendo o surgimento de instituições de caráter formal ou informal. 
Outros valores relacionados ao capital foram identificados no estudo. A busca da visibilidade é um valor presente em todas as subcategorias de autoexpressão e parece ser uma motivação importante para o comportamento bem-humorado. Como apontado anteriormente, a exposição pessoal parece ser uma moeda de troca no ambiente virtual como um todo e nesse contexto particular. A legitimação aparece concretamente nos comentários de aprovação, isto é, quando os usuários demonstram estarem de acordo com os comportamentos apresentados por outros. Porém, esses dois valores não foram identificados em outras categorias de análise.

Por fim, o suporte social é o valor mais recorrente no contexto do estudo e pode ser verificado de forma contundente nas seguintes subcategorias: críticas, desaprovação, informações de contato, pedidos de ajuda, opinião, orientação, aconselhamento, esclarecimento, mensagens de apoio, prestação de ajuda e recomendações. Nessas subcategorias, o suporte social aparece ora como um valor a ser alcançado (até mesmo involuntariamente), ora como uma manifestação explícita de apoio em relação às situações relatadas.

No que se refere à influência do conteúdo do vídeo Depressão sobre a formação do capital social, pode-se considerar que o conteúdo é capaz de gerar a identificação dos usuários e, consequentemente, mobilizar uma série de comportamentos que podem ou não contribuir para a formação do capital social. A relação com o conteúdo aparece de forma mais explícita nas mensagens da subcategoria reações ao vídeo, mas pode-se afirmar, pelo teor dos comentários publicados, que o conteúdo do vídeo funciona como um catalisador para a construção do capital social.

\section{Referências}

1. Top sites in Brazil [Internet]. San Francisco: Alexa Internet; 2019 [cited 2019 Feb 12]. Available from: https://www.alexa.com/topsites/countries/BR.

2. Recuero R. Capital social em rede: como as redes sociais na internet estão gerando novas formas de capital social. Contemporânea [Internet]. 2012 set. [citado em 2017 mar. 28];10(3):597-617. Disponível em: https://portalseer.ufba.br/index.php/contemporaneaposcom/article/view/6295.

3. Bourdieu P. O capital social: notas provisórias. In: Nogueira MA, Catani A, organizadores. Escritos de educação. 13 ed. Petrópolis: Vozes; 2012. p. 67-9.

4. Matos H. Capital social e comunicação: interfaces e articulações. São Paulo: Summus; 2009.

5. Coleman JS. Social capital in the creation of human capital. Am J Sociol. 1988;94 Suppl:95-120.

6. Putnam R, Leonardi R, Nanetti R. Making democracy work: civic traditions in modern Italy. Princeton: Princeton University Press; 1993.

7. Recuero R. Redes sociais na internet. Porto Alegre: Sulina; 2009.

8. Bertolini S, Bravo G. Social capital, a multidimensional concept [Preprint]. 2004 [citado em 2016 ago 01]:[16 p.]. Disponível em: http://citeseerx.ist.psu.edu/viewdoc/download?doi=10.1.1.197.1952\&rep=re p1\&type $=$ pdf.

9. Montardo SP, Silva TDT. Contém spoiler: performance e consumo no site de rede social temático Filmow. Alceu [Internet]. 2015 jan. [citado em 2017 dez. 17];15(30):117-32. Disponível em: http://revistaalceu. com.puc-rio.br/media/Alceu\%2030\%20pp\%20117\%20a\%20132.pdf.

10. Montardo SP, Silva TDT. Bazinga! Consumo e performance sobre The Big Bang Theory no Filmow. Intexto [Internet]. 2018 jan. [citado em 2017 dez. 07];(41):70-87. Disponível em: http://seer.ufrgs.br/ index.php/intexto/article/view/66081.

11. Recuero R. Um estudo do capital social gerado a partir de redes sociais no Orkut e nos weblogs. Rev FAMECOS [Internet]. 2005 dez. [citado em 2017 abr. 02];(28):88-106. Disponível em: http://dx.doi. org/10.15448/1980-3729.2005.28.3340.

12. Recuero R. Comunidades em redes sociais na internet: um estudo de caso dos fotologs brasileiros. Liinc Rev [Internet]. 2008 mar. [citado em 2017 maio 05];4(1):63-83. Disponível em: http://revista.ibict.br/ liinc/article/view/3150. 
13. Recuero R, Zago G. Em busca das "redes que importam": redes sociais e capital social no Twitter. Líbero [Internet]. 2009 dez [citado em 2017 maio 05];12(24):81-94. Disponível em: http://seer.casperlibero. edu.br/index.php/libero/article/download/498/472.

14. Recuero R, Zago G. A economia do retweet: redes, difusão de informações e capital social no Twitter. Rev Contracampo [Internet]. 2012 jul. [citado em 2017 maio 05];24(1):19-43. Disponível em: http:// periodicos.uff.br/contracampo/article/view/17253.

15. Fragoso S, Recuero R, Amaral A. Teoria fundamentada. Porto Alegre: Sulina; 2011. Métodos de pesquisa para internet. p. 84-111.

16. Ayrolla D. O Projeto [Internet]. Campinas: Science Vlogs Brasil. 2016 fev. 01 [citado em 2017 ago. 20]. Disponível em: http://scienceblogs.com.br/sciencevlogs/2016/02/o-projeto/.

17. Capture from YouTube [Internet]. Melbourne: QSR International; 2013 [cited 2017 Dec 16]. Available from: http://help-ncapture.qsrinternational.com/desktop/topics/capture from youtube.htm.

18. Bertolotti E, Medeiros, RF. Passa demaquilante no teu preconceito: tutoriais de maquiagem como performance Queer no YouTube. ReDoC [Internet]. 2019 jan. [citado em 2019 out. 24]; 3(1):151-76. Disponível em: https://www.e-publicacoes.uerj.br/index.php/re-doc/article/view/40792.

19. Caran GM, Biolchini JCA. Suporte social informacional mediado por grupos no Facebook: um estudo de caso. In: Anais do $16^{\circ}$ Encontro Nacional de Pesquisa em Ciência da Informação; 2015 out. 26-30; João Pessoa, Brasil. João Pessoa: UFPB; 2015 [citado em 2019 nov. 23]. 20 p. Disponível em: http://www. ufpb.br/evento/index.php/enancib2015/enancib2015/paper/view/3040.

20. Wellman B, Gulia M. Net surfers don't ride alone: virtual communities as communities. In: Wellman B, editor. Networks in the global village: life in contemporary communities. Boulder: Westview Press; 1999. p. 331-66.

21. Frohlich DO, Zmyslinski-Seelig A. The presence of social support messages on YouTube videos about inflammatory bowel disease and ostomies. Health Commun [Internet]. 2012 [cited 2019 Oct 24];27(5):421-28. Available from: https://doi.org/10.1080/10410236.2011.606524.

22. Rodrigues A, Silva I, Barros R. Interações geradas a partir da visualização de vídeos em canais educacionais no YouTube. Internet Latent Corpus ] [Internet]. 2017 dez. [citado em 2019 out. 02];7(2):53-71. Disponível em: https://proa.ua.pt/index.php/ilcj/article/view/661.

23. Recuero R. Atos de ameaça a face e a conversação em redes sociais na internet. In: Primo A, organizador. Interações em rede. Porto Alegre: Sulina; 2013. p. 51-70.

24. Quaresma CE. A agressividade nas interações virtuais: análise das estratégias de im/polidez em comentários a uma publicidade veiculada no Youtube [dissertação]. Belo Horizonte: UFMG; 2018.

25. Guedes F, Nicolau M. Os videoclipes interativos e a apropriação dos usuários para compartilhamento no YouTube. In: Médola ASLD, Barbosa, MCS, Souza RA, organizadores. Anais do $18^{\circ} \mathrm{I}$ Congresso de Ciências da Comunicação na Região Nordeste; 2016 July 7-9; Caruaru, Brasil. São Paulo: Intercom; 2016 [citado em 2019 nov. 23]. 15 p. Disponível em: http://www.portalintercom.org.br/anais/nordeste2016/ resumos/R52-0964-1.pdf.

26. Corrêa MV, Rozados, HBF. Comportamento informacional em comunidades virtuais: um estudo netnográfico do grupo de interesses SEER/OJS in Brazil do Facebook. Biblionline [Internet]. 2016 jul. [citado em 2017 dez. 07];12(3):112-25. Disponível em: http://www.periodicos.ufpb.br/ojs/index.php/ biblio/article/view/28172. 